\title{
TRADUZINDO O GÊNERO: GÓGOL, KAFKA E LEM
}

\author{
Olga Donata Guerizoli Kempinska* \\ Universidade Federal Fluminense
}

\begin{abstract}
Resumo: Nesse artigo debruço-me sobre o impacto poético da mudança de gênero gramatical das palavras dentro de um texto literário. Com efeito, as diferenças entre as línguas tornam a tradução do gênero e de sua ambivalência muito difícil de ser transposta. Expressas através das palavras que designam roupas e máquinas, as articulações discursivas do sexo e do gênero, intimamente ligadas às condições culturais de sua construção, podem ser observadas nas narrativas de Nicolai Gógol, Franz Kafka e Stanisław Lem.
\end{abstract}

Palavras-chave: Tradução. Gênero. Identidade.

\section{TRANSLATING GENDER: GOGOL, KAFKA AND LEM}

\begin{abstract}
In this paper, I discuss the poetic impact of the change of the grammatical gender of the words within literary texts. Indeed, the differences between languages make the translation of the gender and of its ambivalence very hard to transpose. Expressed by words designating clothes and machines, the discursive articulations of the sex and of the gender, closely linked to the cultural conditions of its construction, can be observed in the narratives of Nicolai Gogol, Franz Kafka and Stanisław Lem.
\end{abstract}

Keywords: Translation. Gender. Identity.

\footnotetext{
* Possui graduação e mestrado em Filologia Românica pela Uniwersytet Jagiellonski de Cracóvia, Polônia. Doutorou-se em História Social da Cultura pela Pontifícia Universidade Católica do Rio de Janeiro (PUC-Rio), em 2008. Atualmente é professora Adjunta do Departamento de Ciências da Linguagem da Universidade Federal Fluminense (UFF). Niterói, Rio de Janeiro, Brasil. E-mail: olgagkem@gmail.com
} 
"Que decepção perante a perversidade que atribui a jour como a nuit, contraditoriamente, os timbres escuro aqui, ali claro" (MALLARMÉ, 1998, p. 193). Através dessa exclamação bem conhecida, captada em uma estrutura intensamente quiasmática, Mallarmé proclamava a crise do verso, deplorando a falta de motivação sonora das palavras "noite" e "dia" em francês. Parece um tanto decepcionante que aquele poeta, que mais exigiu do verso em termos de uma "remuneração" poética, não tenha estranhado nenhuma das perversidades linguísticas relacionadas ao gênero gramatical das palavras. Do ponto de vista do poeta francês, não apareceria como uma perversidade atribuir, contraditoriamente, o gênero masculino à lua, "der Mond", e o feminino ao sol, "die Sonne", como, de fato, acontece na língua da esposa de Mallarmé, na qual existem $o$ lua e $a$ sol?

Ao refletir sobre os problemas linguísticos da tradução, Roman Jakobson insistia, de fato, na relevância do gênero gramatical para a interpretação do texto e afirmava que "as maneiras de personificar metaforicamente os substantivos inanimados são influenciadas pelo gênero destes" (JAKOBSON, 1995, p. 70). Ele citou inclusive um interessante exemplo de uma criança russa que se espantava durante a leitura de contos alemães "ao descobrir que a Morte, seguramente uma mulher (em russo smert', feminino) era representada por um velho (em alemão der Tod, masculino)" (JAKOBSON, 1995, p. 71). Esse problema do simbolismo dos gêneros interessou também Claude Lévi-Strauss. Ao discriminar a luminosidade, a energia, o calor, o tamanho e até a racionalidade como categorias que são utilizadas em diferentes culturas para opor o sol e a lua, o antropólogo, no intrigante texto "O sexo dos astros", dedicado, aliás, a Jakobson, notou que, apesar da necessidade da afirmação da tensão entre os dois astros, não apenas falta a consequência genérica, tanto na forma das palavras, quanto na sua inserção nos mitos, como também que "na ideologia de várias populações, o sexo do astro parece instável” (LÉVI-STRAUSS, 1976, p. 223). Uma sensibilidade ao potencial poético do gênero gramatical das palavras será encontrada também em Barthes, que enfatizou, por 
exemplo, a feminilidade presente no nome Sarrasine, "perceptível a todo francês, que acolhe espontaneamente o $e$ final como um morfema específico do feminino" (BARTHES, 1970, p. 24), e que capta a inversão gráfico-genérica presente no nome do protagonista de Balzac: "Além do mais, $\mathrm{S}$ e $\mathrm{Z}$ estão em uma relação de inversão gráfica: é a mesma letra vista do outro lado do espelho" (BARTHES, 1970, p. 113).

Foi no contexto da reflexão sobre a "perversidade" linguística que envolve o gênero gramatical das palavras e sobre suas inversões semânticas que chamaram minha atenção algumas ocorrências de mudanças genéricas presentes nos textos de Nicolai Gógol, Franz Kafka e Stanisław Lem. Trata-se de casos de substituição do nome de um objeto, que provoca também uma mudança do gênero gramatical da palavra - movimento às vezes não imediatamente perceptível numa primeira leitura e que coloca desafios especialmente espinhosos ao tradutor. E se essa substituição, longe de remeter a uma simples sinonímia, faz questionar, antes, à motivação genérica das palavras, é porque os “objetos" afetados pela mudança têm um papel protagonista dentro das narrativas em questão e, como veremos, ao trocarem de nome e de gênero, parecem trocar também de identidade.

Enquanto uma contribuição para a reflexão sobre o alcance da poética, este estudo se propõe demonstrar os motivos da necessidade de se arriscar uma ampliação do elenco das operações linguísticas responsáveis por aquilo que Roman Jakobson chamava de "função poética" (JAKOBSON, 1995, p. 128) e, eventualmente, sua abertura aos jogos linguísticos com o gênero gramatical das palavras. De fato, o gênero gramatical da palavra pode ter uma participação muito relevante na exposição da materialidade da linguagem, e, com isso, na estimulação dos florescimentos de ambiguidades da referência. 


\section{O gênero do capote}

No Capote de Nikolai Gógol, de 1842, a narrativa inaugural da literatura russa, que conta a estranha história do pobre funcionário Akáki Akakievitch e as consequências nefastas de sua decisão de substituir sua velha vestimenta por uma nova, o objeto que muda de nome e, ao mesmo tempo, de gênero gramatical e de identidade é a própria vestimenta. A distinção entre as duas peças de vestuário, a velha, que não apenas não protegia o protagonista do frio, mas, ainda, o expunha ao escárnio social, e a nova, que o valorizava e afirmava, tanto física, quanto espiritual e socialmente, é, a meu ver, essencial na organização poética do conto de Gógol.

Mas como exatamente a vestimenta de Akáki muda de nome? Em russo, o título da narrativa é Шинель (Cf. GÓGOL, 2007), e a "иинель" [Jiniel], figura da vestimenta valorizante, opõe-se ao longo da história ao "kanom" [kapot], que remete à vestimenta degradante. A vestimenta valorizante é em russo uma palavra feminina, enquanto que a desvalorizante é uma palavra de gênero masculino. A tradução das palavras que remetem às duas vestimentas de Akáki, de fato, apresenta diversos desafios, que dizem respeito à dificuldade de se preservar o movimento do sentido da narrativa, e que começam pela tradução de seu título.

Na primeira parte do conto, é justamente a "шинель" de Akáki que, por causa de sua usura, é chamada de forma denegridora de "kanom". Na tradução em português, ocorre nessa passagem uma troca curiosa: a palavra "capote" é usada para transpor a "uuнель" , enquanto a palavra "roupão" é usada para o "каnоm", palavra, que, no entanto, é mais próxima foneticamente do "capote". Assim, na tradução de Maria Aparecida Botelho Pereira Soares temos: "tinham-lhe negado até a denominação nobre de capote e chamavam-no de roupão" (GÓGOL, 1986, p. 18), enquanto na tradução de Paulo Bezerra a mesma passagem diz: "tiraram-lhe inclusive o nobre nome de capote substituindo-o por roupão." (GÓGOL, 2010, p. 14). Já na tradução de Roberto Gomes, a palavra "capote" preserva seu lugar na sequência, enquanto "шинель" é 
traduzida como "casaco": "Haviam mesmo retirado a nobre denominação de casaco para tratá-lo desdenhosamente por "capote" " (GÓGOL, 2000, p. 17). Nesse caso, que preserva o lugar do "capote" no original, no qual este remete à vestimenta desvalorizante, infelizmente, é o título que não parece adequado, pois, em russo, este remete claramente à vestimenta valorizante.

Por que essa mudança de nome é tão relevante na poética do conto de Gógol? Porque a confecção da nova vestimenta produz mudanças inesperadas e exorbitantes em Akáki, de modo que o pobre funcionário parece estar se reinventando em profundidade por meio da reinvenção de sua aparência. Colocado, de repente, no domínio do individualismo e, ao mesmo tempo, no domínio do parecer e do prazer, Akáki descobre algo da natureza febril da moda, sempre "inseparável do excesso, da desmedida, do exagero" (LIPOVETSKY, 2009, p. 40). A nova vestimenta é para o protagonista um excesso por excelência e faz com que ele ultrapasse todos os seus limites: existenciais, econômicos, estéticos, sociais e, como veremos, genéricos. Sua transformação sob o efeito da nova vestimenta oscila grotescamente entre um delírio narcisista, uma loucura amorosa e uma possessão demoníaca.

Nesse contexto de metamorfose do protagonista, a tradução da palavra "นинель" como "capote" apresenta ainda um problema: "шинель" é em russo uma palavra do gênero feminino, enquanto "capote" é masculino. Essa diferença não me parece irrelevante no conto de Gógol, pois a decisão de encomendar uma nova casaca, transforma-se para Akáki em uma verdadeira coabitação amorosa:

Desde então foi como se sua própria existência tivesse adquirido mais plenitude, como se ele houvesse se casado, como se contasse com outra pessoa a seu lado, como se não estivesse sozinho e uma simpática companheira tivesse concordado em percorrerem juntos a estrada da vida - e essa companheira não era outra senão o capote novo de algodão grosso e forro resistente. (GÓGOL, 2010, p. 22) 
A esposa, a casaca, a matéria, a tela protetora, parecida com uma nova pele, um novo "eu-pele" (ANZIEU, 1995): todos esses elementos da convivência de Akáki com a nova vestimenta remetem a seus efeitos benfazejos. A casaca parece para Akáki como uma mãe-esposa. Vladimir Nabokov descreveu em sua biografia de Gógol uma analogia curiosa entre o Capote e um dos contos folclórico-oníricos do autor ucraniano, intitulado Ivan Shponka e sua Tia:

Veja, por exemplo, o sonho de Ivan Shponka - um dono de terras ucraniano, submisso e impotente, cuja tia dominadora tentava forçá-lo a casar com uma loira arrogante, filha do vizinho. “(...) Então ele sonhou que uma esposa não era uma pessoa viva, mas uma espécie de tecido de lã, e que ele estava entrando numa loja de um comerciante em Moguiliov. 'Que tipo de tecido o senhor deseja?', perguntou o comerciante, e continuou: 'Seria melhor o senhor levar uma esposa, é o material mais em moda, e também é muito resistente - hoje em dia, todos os cavalheiros estão fazendo casacos dele' - e o comerciante começou a medir e a cortar a esposa." (NABOKOV, 1994, pp. 29-30)

O sonho-pesadelo do conto gogoliano, no qual a esposa é a lã, matéria para a fabricação do casaco, remete também ao jogo chistoso com a expressão idiomática "material para uma boa esposa". No entanto, no Capote, tal como no sonho de Ivan, a matéria-esposa rapidamente perde seu caráter benéfico, transformando-se na origem de um mal. É justamente a casaca, roubada na primeira noite de seu uso, que levará à exposição do protagonista ao frio extremo e ao desespero, provocando sua morte e sua transformação em um fantasma, ladrão de casacas.

A vestimenta representada no conto de Gógol aparece, com efeito, como reversível e seu desdobramento poético-genérico "casaca/ capote" abre o caminho para uma série de outros pares reversíveis: roupa/corpo, corpo/fantasma, morte/vida, natureza/artifício, feminino/masculino. Afetada pelo princípio da reversibilidade, a 
identidade genérica representada na narrativa gogoliana pode ser colocada em relação com a representação do sexo reversível e do corpo humano dotado de sexo único, tal como descrita por Thomas Laqueur no livro Making Sex, Body and Gender from the Greeks to Freud. Em contraposição à ideia, aparentemente óbvia, segundo a qual o sexo biológico determinaria o gênero, Laqueur mostra como as condições culturais influenciaram, ao longo dos séculos, as imagens anatômicas dos órgãos genitais. "Tal como mapas, as ilustrações anatômicas chamam atenção para um detalhe particular ou para um conjunto de relações espaciais" (LAQUEUR, 1992, p. 164), nota Laqueur, e, ao demonstrar que a anatomia sempre dependeu da representação, distingue dois sistemas de representação do sexo: o modelo de um sexo único e o modelo de dois sexos distintos. Será apenas a partir dos meados século XVIII que a descoberta dos ovários e a dissociação entre a fecundação e o orgasmo feminino passarão a impulsionar a elaboração da representação de dois sexos radicalmente diferentes, incomensuráveis, opostos. Antes dessa época, predominava no Ocidente o modelo de um único sexo, construído ao longo dos séculos pelos discursos sobre a androginia original do ser humano, sobre os fluídos na Antiguidade e, finalmente, pelo discurso da medicina clássica e renascentista sobre o isomorfismo dos órgãos sexuais masculinos e femininos.

O movimento da reversibilidade desenfreada no conto de Gógol, que faz com que a casaca seja uma in-versão do capote, a vestimenta uma in-versão o corpo e o corpo uma in-versão do fantasma, pode ser interpretada como uma transposição da representação tradicional dos sexos reversíveis. A mulher é, segundo essa representação, "um homem invertido" (LAQUEUR, 1992, p. 27), tal como os órgãos sexuais femininos são, segundo as ilustrações anatômicas renascentistas, uma mera inversão dos órgãos masculinos. Tal como a mulher-vestimenta do conto de Gógol, que, submetida a uma série de gestos de in-versão, acaba sendo uma in-versão de Akáki, a representação do sexo feminino, inserida dentro do sistema da história social da cultura, no qual crer é ver, aparece, de fato, como uma in-versão do sexo masculino. 


\section{O gênero da máquina}

Uma ambivalência relacionada ao gênero, que lembra a in-versão gogoliana, pode ser observada também na narrativa Colônia penal de Franz Kafka, de 1914. Também nesse texto, seu/sua protagonista tácito/a, que é o aparelho/a máquina de execução dos condenados em uma colônia penal, muda de nome e de gênero. E tal como no caso da vestimenta do conto de Gógol, a troca de gênero gramatical na narrativa kafkiana claramente aponta para uma mudança de função e de identidade.

$\mathrm{Na}$ primeira parte do texto, que começa com a introdução do dispositivo em cena - "É um aparelho singular - disse o oficial ao explorador, percorrendo com um olhar até certo ponto de admiração o aparelho que ele no entanto conhecia bem" (KAFKA, 2007, p. 29) -, quando sua estrutura e seu funcionamento estão sendo descritos pelo comandante de modo exageradamente detalhado, o dispositivo, que inscreve no corpo dos condenados o texto da lei infringida, é consequentemente chamado de "aparelho" (der Apparat). Mas quando, alimentado com a carne do condenado, "o aparelho" ultrapassa sua fase teórica da minuciosa descrição e se põe em marcha, passa a ser chamado de "máquina" (die Machine): "O explorador tinha inclinado o ouvido para o oficial e, as mãos no bolso da jaqueta, observava o trabalho da máquina" (KAFKA, 2007, p. 45).

Essa troca de nome e de gênero - do masculino para o feminino -, muito consequente no texto de Kafka bastante bem seguida na tradução em português de Modesto Carone -, é relevante na medida em que aponta para a passagem da passividade à atividade, movimento contrário à representação historicamente afirmada das atitudes, reprodutivas e sociais, atribuídas aos gêneros. À primeira vista, enquanto $o$ aparelho é objeto passivo da descrição do comandante, $a$ máquina responde pela atividade de seu funcionamento.

Mas o jogo com a in-versão da relação entre a passividade e a atividade escapa, na narrativa de Kafka, a uma determinação simples, revelando-se dinamicamente subversiva, na medida em 
que impossibilita a imobilização da oposição. O funcionamento da máquina é, na verdade, rapidamente invertido em uma disfunção, que leva a sua autodesmontagem espetacular durante a relação com o corpo do comandante. E, em um movimento de in-versão grotesca entre o corpo e o objeto, a máquina torna-se mortífera para seu operador-vítima, seu último e seu único executado voluntário, que, pelo excesso da auto-execução, parece ter querido afirmar sua identidade com a máquina.

A falha da máquina kafkiana e sua autodeconstrução apontam, por sua vez, para a própria negação da característica de toda máquina, a saber, a previsibilidade de seu funcionamento em termos racionais. E é justamente a articulação da negação dessa característica, a previsibilidade racional, com a troca de gênero, que retorna em duas narrativas de ficção científica de Stanisław Lem dedicadas ao tema da poieisis.

Entre os mais curiosos dentre os contos lemianos, chama, de fato, a atenção aquele intitulado "Como foi salvo o mundo", de 1975, que coloca em cena o problema, comum à filosofia, à poética da criação e à história da sexualidade, da precedência da ideia com relação à existência da realidade material. Para encenar os limites desse princípio formal, a narrativa lemiana representa a construção de uma máquina produtora de objetos que começam com uma determinada letra. Em polonês, a letra que determina a produção da máquina é $n$, mas optei pelo $c$ em português por motivos poéticos:

O Construtor Trurl construiu uma vez uma máquina que sabia fazer tudo que começava com a letra $c$. Quando estava pronta, para testá-la, ordenou que fizesse cordões e, depois, que os cacheasse nos carretéis, o que ela fez, e, em seguida, que os jogasse dentro de uma previamente preparada cova, rodeada de chuveiros, catenárias e compressões. (LEM, 1975, p. 121)

Após essas primeiras façanhas, a máquina teve ainda de continuar o teste, aumentando o grau de dificuldade do fazer e con- 
feccionado "céu”, “ciência” e "contrário". Nesse último caso, "primeiro fez antiprótons, em seguida antielétrons, antineutrinos, antinêutrons e continuou trabalhando desse jeito criando muita antimatéria, da qual começava surgir aos poucos, parecido com uma nuvem de brilho estranho no céu, um anti-mundo. " (LEM, 1975, p. 122). Depois desse espetáculo da antimatéria, para completar a prova de produção da realidade, o desafio da máquina consistiu em fazer "coisa nenhuma". Este fazer revelou-se, no entanto, extremamente perigoso, pois o mundo, submetido à lei da carência e do caos, começou a desaparecer: "A máquina, de fato, estava fazendo coisa nenhuma, de modo que, uma por uma, eliminava do mundo diversas coisas, que deixavam de ser como se nunca tivessem existido." (LEM, 1975, p. 123). E mesmo que a máquina tenha, finalmente, deixado de produzir "coisa nenhuma", e que o mundo tenha sido salvo da produção às avessas da matéria, a realidade permaneceu, no entanto, toda "furada", perpassada por "coisa nenhuma" e algumas coisas desapareceram dela para sempre.

Não que na realidade sociohistórica contemporânea dos contos de Lem tivesse existido a obsolescência programada ou que seus dispositivos fossem gadgets lúdicos de temporada, mas a máquina do conto "Como foi salvo o mundo" será rapidamente substituída por uma nova experiência. O tema da construção da máquina criadora e do crescendo de seus testes retorna, de fato, na mesma coletânea dos contos de Lem, na narrativa "A expedição 1a ou o Eletrobalb de Trurl”. Mas, dessa vez, o cientista constrói uma máquina poeta. O desafio consiste na programação de um aparelho que pudesse abranger toda a história da humanidade, o que resulta em uma construção pitorescamente babélica, parecida com "uma pequena cidade de fios emaranhados e lâmpadas" (LEM, 1975, p. 136). Interessante é também que, dessa vez, na situação que envolve não a produção da matéria do mundo, mas a criação da arte, a máquina, que no conto anterior era simplesmente "maszyna", palavra feminina em polonês, parece ter agora o sexo masculino, refletido em seu nome Eletrobalb. Um aparelho, no masculino, é, como no conto de Kafka, responsável pela ideação e não pelo contato, dis- 
funcional, com a matéria. Não mais $a$ máquina, mas $o$ eletropoeta lemiano passa a ameaçar com a qualidade de sua produção os poetas humanos, suscita inveja e raiva do meio artístico e, em um gesto, que ironicamente lembra a expulsão platônica do poeta da cidade, é enviado para o espaço sideral, no qual se torna "o motor lírico de um grupo de estrelas explosivas” (LEM, 1975, p. 146).

No caso desses dois contos, chama a atenção a composição paralela com vários elementos em comum: a construção do dispositivo pelo mesmo personagem, o cientista chamado Trurl, a atribuição de tarefas que consistem em uma poieisis, e, finalmente, as peripécias relacionadas com os excessos de seu funcionamento. Não andróides - e a representação do gênero feminino na obra de Lem pode ser analisada não apenas através da reflexão sobre o sexo das máquinas, mas, sobretudo, através do estudo da representação dos androides e dos extraterrestres (Cf. GLASENAPP, 2003) -, as duas máquinas lemianas, a fabricadora de matéria e o fabricador de poemas, passam também a ameaçar os domínios humanos de suas respectivas atividades. Mas há uma diferença considerável na natureza e na dimensão dos danos produzidos pelas duas máquinas, que, ambas, excedem-se em seus fazeres, apontando com isso para os limites da racionalidade da programação e para a liberação da "sexualidade subjugada" (BAUDRILLARD, 1968, pp. 172-173). Ao passo que o poeta eletrônico não apresenta defeitos de funcionamento e apenas ameaça o mundo da literatura e da edição, desvelando, dessa forma, os vícios internos desse meio, a máquina fabricadora da matéria, desprovida de nome próprio e responsável por uma verdadeira anti-poieisis, ameaça com seus excessos a prórpia existência da realidade.

\section{A poética do gênero}

Através de sua duplicidade e da diferença no que tange a sua poieisis, as máquinas lemianas evidenciam a existência de uma diferença fundamental com relação tanto à máquina kafkiana, quanto 
à vestimenta gogoliana. Ao contrário do/da capote/casaca e aparelho/máquina, a dupla dos dispositivos dos contos de Lem, “a máquina" e o Eletrobalb, parecem, de fato, resistir ao movimento de reversibilidade. "A máquina", de gênero feminino e cuja aparência física nem é descrita, ao contrário do "corpo" labiríntico-babélico do Eletrobalb, aparece como radicalmente distinta do aparelho-poeta. Sua função, sobretudo, é muito diferente, pois ela não cria, ela produz. A representação do sexo e do gênero em Lem aproxima-se, com isso, não mais da visão do sexo único e reversível, mas, antes, da representação, construída pelo discurso científico desde o Iluminismo, passando por Darwin até Freud, dos dois sexos distintos, cujas diferenças anatômicas, fisiológicas e mentais são irredutíveis (Cf. LAQUEUR, 1992, pp. 205-256).

"O assim chamado sexo biológico não fornece fundamento sólido para a categoria cultural do gênero, antes constantemente ameaça subvertê-la" (LAQUEUR, 1992, p. 124), nota Laqueur, desvelando a presença de uma poieisis na fabricação da representação tanto do sexo quanto do gênero. A reflexão sobre a relevância, nos textos literários, de representações dos objetos, cujo nome é instável e cujo gênero gramatical e papel desempenhado na narrativa aparecem como intercambiáveis, de fato, aponta para a importância do discurso na construção não apenas do gênero cultural, mas também do sexo biológico.

A reversibilidade e a ambivalência genéricas, frequentemente estudadas no exemplo dos nomes próprios, mostram-se como particularmente fascinantes quando atingem objetos cotidianos. "Por detrás de cada objeto real, existe um objeto sonhado" (BAUDRILLARD, 1968, p. 165), notou Jean Baudrillard, insistindo na capacidade de se colocar entre parêntese a função prática e limitada dos objetos de uso diário e de se abrir o espaço para um jogo mental ilimitado. A poética do gênero abrange nas narrativas de Gógol, Lem e Kafka objetos que, através de uma projeção imaginária, têm sua função prática amplamente extrapolada e que passam a se constituir em representações mais imediatas dos excessos do sujeito. Tanto as roupas quanto as máquinas fazem 
parte das "técnicas" (DERRIDA, 2002, p. 17) que não existem na natureza e que servem para delimitar o humano do animal e o masculino e do feminino. E não é por acaso que os objetos em questão sejam aqueles que são também os mais vulneráveis à moda: o vestuário em Gógol, uma máquina mecânica em Kafka e as máquinas eletrônicas em Lem. Com efeito, são esses objetos, os mais representativos do sistema da moda hoje em dia, moda "que é o próprio movimento de um perpétuo exceder-se" (N'DIAYE, 1989, p. 32), que, ao servirem frequentemente à domesticação imaginária do sexo, se tornam também mais propensos ao desvelamento dos agenciamentos de sua representação.

\section{Referências}

ANZIEU, Didier. Le Moi-peau. Paris: Dunod, 1995.

BARTHES, Roland. S/Z. Paris: Seuil, 1970.

BAUDRILLARD, Jean. Le système des objets. Paris: Gallimard, 1968.

DAVID-MÉNARD, Monique, DEUTSCHER, Penelope. Gender. In. CASSIN, Barbara (org.) Vocabulaire européen des philosophies. Paris: Seuil\&Le Robert, 2004, pp. 495-497.

DERRIDA, Jacques. $O$ animal que logo sou (A seguir). São Paulo: UNESP, 2002. Trad. Fábio Landa.

GLASENAPP, Małgorzata. "Femina astralis - kobiecość w powieściach fantastycznonaukowych Stanisława Lema”. In. JARZĘBSKI, Jerzy (org.). Stanistaw Lem: pisarz myśliciel, człowiek. Kraków: Wydawnictwo Literackie, 2003, pp. 256-275. 
GÓGOL, Nicolai. Повести. Москва: Мир Книги, 2007.

Aparecida Botelho Pereira Soares.

. O Capote. Rio de Janeiro: Alhambra, 1986. Trad. Maria . O Capote e outras histórias. São Paulo: Editora 34, 2010. Trad. Paulo Bezerra.

. O Capote seguido de O retrato. Porto Alegre: LP\&M Pocket, 2008. Trad. Roberto Gomes.

JAKOBSON, Roman. Linguística e Comunicação. São Paulo: Cultrix, 1995. Trad. Izidoro Blikstein e José Paulo Paes.

KAFKA, Franz.Das Werk. Sämtliche Werke. Frankfurt am Main: Zweitausendeins, 2004.

$O$ Veredito. Na colônia penal. Trad. Modesto Carone. São Paulo: Companhia das Letras, 2007.

LAQUEUR, Thomas. Making Sex, Body and Gender from the Greeks to Freud. Cambridge: Harvard University Press, 1992.

LEM, Stanisław. Opowiadania wybrane. Kraków: Wydawnictwo Literackie, 1975.

LÉVI-STRAUSS, Claude. Antropologia estrutural dois. Rio de Janeiro: Tempo Brasileiro: 1976. Trad. Maria do Carmo Pandolfo.

LIPOVETSKY, Gilles. O império do efêmero. A moda e seu destino nas sociedades modernas. São Paulo: Companhia das Letras, 2009. Trad. Maria Lucia Machado.

MALLARMÉ, Stéphane. Poésies et autres textes. Paris: Librairie Génerale Française, 1998. 
N'DIAYE, Catherine. A coquetterie ou a paixão do pormenor. Lisboa: Edições 70, 1989. Trad. Artur Lopes Cardoso.

NABOKOV, Vladimir. Nicolai Gógol. Uma biografia. São Paulo: Ars Poética, 1994. Trad. Terezinha Barretti Mascarenhas.

Recebido em: 13/10/2014 Aceito em: 02/01/2015 